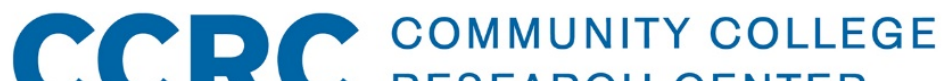 RESEARCH CENTER
}

TEACHERS COLLEGE, COLUMBIA UNIVERSITY

\section{Happy Together? The Peer Effects of Dual Enrollment Students on Community College Student Outcomes}

\author{
Vivian Yuen Ting Liu \\ Community College Research Center \\ Teachers College, Columbia University \\ Di Xu \\ University of California, Irvine
}

December 2019

CCRC Working Paper No. 116

Address correspondence to:

Vivian Yuen Ting Liu

Postdoctoral Research Associate, Community College Research Center

Teachers College, Columbia University

525 W. 120th St., Box 174

212-678-6639

Email:yt12102@tc.edu

Funding for this research was provided by Ascendium Education Group. We are grateful for the excellent feedback on prior drafts from Thomas Brock, Judith Scott-Clayton, Michel Grosz, Dylan Conger, and attendees at the 2019 Association for Education Finance and Policy annual conference and the 2019 Association for Public Policy Analysis and Management annual conference. We are also grateful for the editing expertise of Hayley Glatter and Andrew Beenken. All errors are our own. The opinions expressed are those of the authors and do not necessarily represent views of the funder. 


\begin{abstract}
Nationally, $15 \%$ of first-time community college students were high school students taking college coursework through dual enrollment (DE) in the fall of 2010, and the percentage has risen since then. The growing numbers of DE students at community colleges raises concerns about how high school peers might influence traditionally aged college enrollees. Using administrative data from a large state community college system, we examine whether being exposed to a higher percentage of DE peers influences nonDE enrollees' performance in college courses. Focusing on entry-level (or gateway) math and English courses and employing a two-way fixed effects model, we find that non-DE college enrollees exposed to a higher proportion of DE peers had lower pass rates and grades in gateway courses, and higher course repetition and lower subject persistence.
\end{abstract}




\section{Table of Contents}

1. Introduction ............................................................................................................................. 1

2. National Trends in Dual Enrollment and Relevant Literature ..............................5

2.1 The Growth of Dual Enrollment ............................................................................. 5

2.2. How DE Peers May Influence College Students ................................................... 5

2.3 The Current Study................................................................................... 8

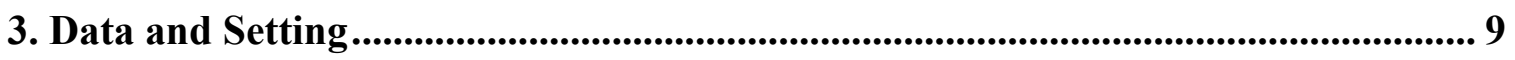

3.1 State Context in Dual Enrollment .................................................................. 9

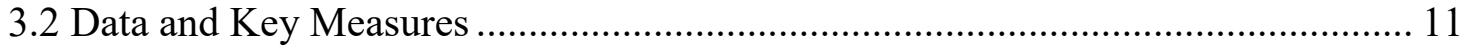

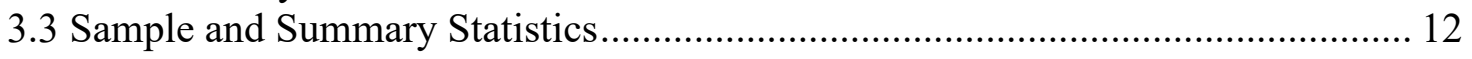

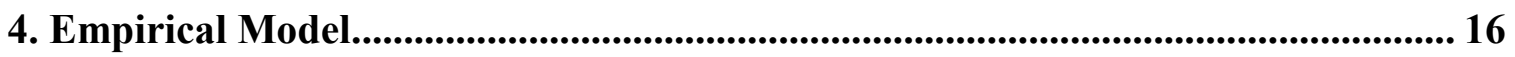

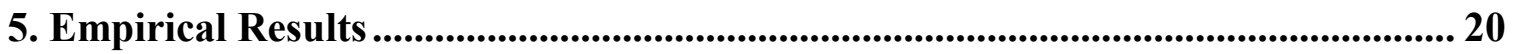

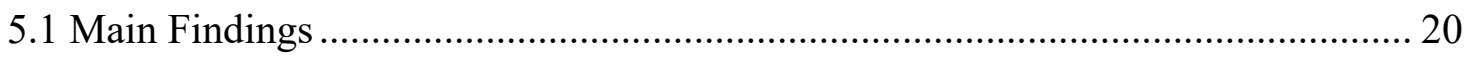

5.2 Heterogeneity by Student Prior Academic Performance ...................................... 22

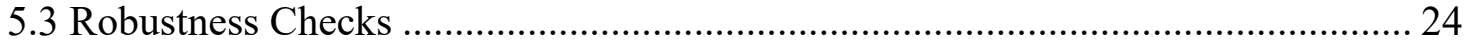

6. Discussion and Conclusion ...................................................................................... 27

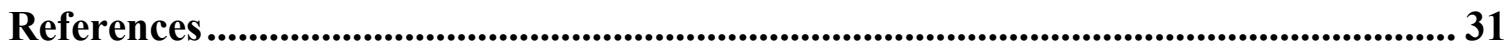

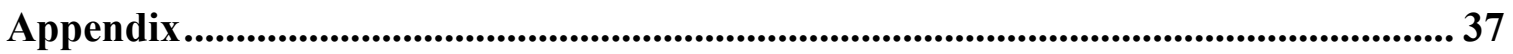





\section{Introduction}

In the fall of 2010 , more than $15 \%$ of first-time community college students across the nation were high school students taking college coursework through dual enrollment (DE), and there is strong evidence that the number of DE students at community colleges has continued to increase since then (Fink, Jenkins, \& Yanagiura, 2017). Researchers have noted several benefits of these programs for high school students, including that they may increase students' competitive edge in the college application process, better prepare students for college coursework and therefore ease students' transition from high school to college, and reduce the costs and time it takes to earn a postsecondary degree (e.g., Allen \& Dadgar, 2012; An, 2013; An \& Taylor, 2019; Giani, Alexander, \& Reyes; 2014; Miller et al., 2018; Jones, 2014; Speroni, 2011; Karp, Calcagno, Hughes, Jeong, \& Bailey, 2007).

In contrast to the general agreement that DE benefits high school students, the potential impacts of DE on "non-DE" college students (i.e., on those enrolled as regularly matriculating college students who are not also enrolled in high school) ${ }^{1}$ and on colleges are mixed. On the one hand, advocates of DE point out that community colleges may also benefit from the current DE expansion by helping them maintain relatively stable enrollments in the midst of broader postsecondary enrollment declines (Smith, 2017). Additionally, since DE students are often well prepared academically, they may also serve as a positive influence on their community college classmates, thus bringing positive externalities to their peers (Smith, 2017). On the other hand, college administrators have expressed concerns over the extra burden added to instructors to help DE students adjust to college (Jenkins, 2013; Reed, 2018). Since DE students are younger and are new to the college environment, instructors may need to take extra time and effort to help DE students with both academic and logistical matters, such as book purchases, transportation problems, and conflicts between high school activities and college course schedules (Conley, 2008; Hughes \& Edwards, 2012), thereby leaving the other students with less attention and support. Having a greater proportion of younger peers in the classroom may also influence classroom dynamics and peer interactions, making some

\footnotetext{
${ }^{1}$ Non-DE college students may themselves have had experience as DE students before they matriculated at college. We address this circumstance later in the analysis.
} 
activities, such as group projects, more challenging (Catron, 2001). Furthermore, the presence of more higher performing DE students in a course may serve to lower non-DE community college students' grades since many instructors grade students on a normal distribution curve.

There is little empirical evidence regarding the impact of DE peers on the academic outcomes of non-DE college enrollees, yet understanding the externalities of DE peers is important for three reasons. First, DE participation has been increasing steadily during the past decade. In the state where the current study is conducted, for example, the statistics shown in Figure 1 indicate that the presence of DE students in community colleges tripled between 2014 and 2016, hitting close to $18 \%$ of total enrollment in 2016. DE participation is likely to continue to grow given rising tuition costs and the increasing value of a college degree.

Figure 1.

Proportion of DE Students Among Two- and Four-Year Public College Students in the State

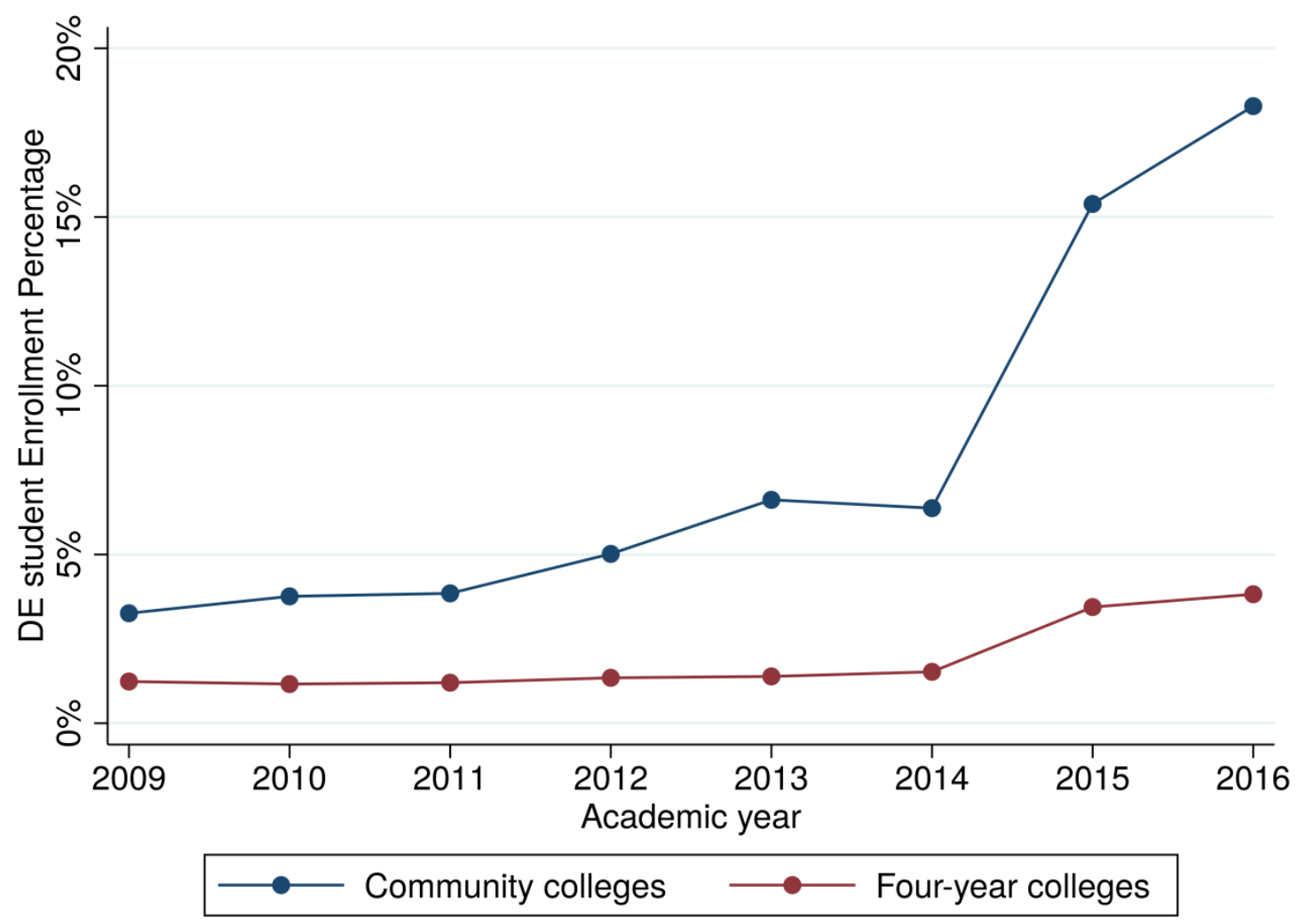

Note. Each point represents the proportion of DE students as a percentage of the total public college student count per year. The sample includes all students enrolled in the state in each academic year. 
Second, community colleges play an important role in addressing the national equity agenda by serving a large proportion of students from underserved minority and low-income backgrounds (Horn \& Nevill, 2006). Yet DE students are more likely to be White or Asian and from more affluent backgrounds (Fink, 2018; Fink et al., 2017). Therefore, if serving DE students comes at the cost of non-DE community college enrollees' educational resources and academic achievement, the expansion of DE programs may further exacerbate educational inequities between different subpopulations.

Lastly, peer effects have long been an interest of economists and policymakers. Understanding the possible positive and negative externalities of one group of students on another and on college functioning is especially crucial in forming policy and optimizing organizations to maximize education outcomes for each education dollar spent (often in the midst of shrinking budgets). Despite the large volume of studies on peer effects conducted in K-12 and four-year postsecondary settings, there is virtually no research on the topic in community colleges. Recent studies have shown the importance of instructor characteristics and quality on the learning outcomes of community college students (e.g., Ran \& Xu, 2018; Xu, 2019), so it is reasonable to also consider how peer characteristics may influence student achievement in the community college setting.

This study provides the first empirical evidence on the effect of DE peers on the academic outcomes of non-DE community college enrollees. It is based on analysis using an administrative dataset of student transcript records from 2012 to 2017 in a large community college system in an anonymous state. Specifically, we estimate the effect of being exposed to a higher percentage of DE peers on non-DE community college students' performance in math and English gateway courses. We also estimate downstream outcomes, including course repetition and enrollment in other courses within the same subject area. We focus on math and English gateway courses because they are the most popular courses among DE students. Additionally, these introductory courses are essential prerequisites for most degrees and certificates at community colleges, so students who pass these courses are substantially more likely to earn a postsecondary credential (Calcagno, Crosta, Bailey, \& Jenkins, 2007). As a result, community colleges tend to be particularly concerned with success rates in these courses and how to improve 
them (Herzog, 2005). If exposure to DE peers affects the performance of non-DE students in gateway courses, then these short-term impacts may grow into a profound longer term influence on a student's academic pathway, degree attainment, and labor market outcomes.

We begin by documenting the differences in observable characteristics between DE students and non-DE community college enrollees. Descriptive statistics show that DE students are more likely to be female, White, and younger, and to perform better academically than non-DE community college enrollees. These demographic differences are consistent with the existing literature indicating that DE students tend to be higher achieving, White or Asian, and from more affluent backgrounds (Fink, 2018; Fink et al., 2017).

We then move to the main research question of this study: How does exposure to a greater proportion of DE peers influence non-DE community college students' performance in gateway math and English, and what are the subsequent downstream outcomes of that influence? Credibly estimating the externalities of DE students is difficult due to methodological challenges. Since students are not randomly assigned to classes at community colleges, it is difficult to separate exogenous peer effects from student self-selection into different classes. To minimize bias from student self-sorting, we implement a two-way fixed effects model, which controls for both individual-level and course-level fixed effects and therefore addresses any sorting that is fixed either at the student level, such as academic preparation and motivation, or at the course level, such as course content and difficulty.

Although the effect sizes are fairly small, our results indicate that exposure to a greater proportion of DE peers has a negative influence on community college students' probability of passing the gateway courses and on their course grades. In terms of downstream outcomes, community college students exposed to a greater proportion of DE peers are more likely to repeat the course and less likely to take other courses in the same field of study. Additional heterogeneity analyses by student first-term GPA indicate that the negative externalities from DE peers are most pronounced among community college students who are within the lowest and middle range of the prior academic performance distribution. 


\section{National Trends in Dual Enrollment and Relevant Literature}

\subsection{The Growth of Dual Enrollment}

Dual enrollment, also called concurrent enrollment, refers to programs that allow high school students to enroll in college courses and earn college credits while they are in high school. DE has existed as a college acceleration opportunity for decades (Andrews \& Marshall, 1991; Gerber, 1987; Mokher \& McLendon, 2009), and its popularity has grown significantly since the early 1990s when more emphasis began to be placed on college readiness and when college tuition began to increase steadily (Karp, 2012). A number of studies have used quasi-experimental designs to estimate the impact of DE participation on high school students' academic choices and postsecondary success (e.g., Allen \& Dadgar, 2012; An, 2013; Giani et al., 2014; Hemelt, Schwartz, \& Dynarski, 2019; Miller et al., 2018; Speroni, 2011). With the exception of Speroni (2011), all found that DE participation had a positive impact on students' postsecondary enrollment and performance.

The fast expansion of DE programs, however, has not affected all students equally. A number of reports have identified noticeable disparities across subpopulations in both access to and actual participation in DE (e.g., U.S. Government Accountability Office, 2018). Studies have typically found that DE students are more likely than their non-DE peers to be high income, female, White, Asian, and high achieving (Fink, 2018; Fink et al., 2017). In an effort to close equity gaps in DE participation, many practitioners and policymakers have advocated for the expansion of DE programs nationwide, especially among students enrolled in low-income districts. The Education Commission of the States (Zinth \& Barnett, 2018), in particular, has called for broadening DE access to both middle- and low-achieving students by increasing their exposure to DE courses and changing the eligibility requirements for participation.

\subsection{How DE Peers May Influence College Students}

Concomitant with the national efforts to increase DE access and participation, the growing number of high school students in college classrooms has raised concerns regarding whether and how non-DE community college students might be influenced by their younger high school peers. Survey data with college faculty indicate that DE 
students often need additional support as a result of the structural, cultural, and functional differences between high school and college (Conley, 2008). For example, some instructors have noted that DE students lack self-directed learning skills, such as skills associated with time management, note-taking, and out-of-class study. As a result, course instructors often need to provide extra assistance to help DE students adapt to the college learning environment (Hughes \& Edwards, 2012). Indeed, community college instructors sometimes need to develop age-appropriate course syllabi, choose different textbooks, and work with high school teachers to cater to particular needs of DE students (Catron, 2001). The additional attention from instructors and the course adjustments made for DE students may influence the level of support non-DE community college students receive. Yet, despite the critical importance of this issue for educational policy, there is surprisingly little rigorous evidence on how DE peers influence the learning experiences and outcomes of non-DE community college enrollees.

While empirical evidence on the impact of DE peers on non-DE community college enrollees is generally missing from the existing literature, we do know that, generally, peers' backgrounds and behaviors can directly influence students' educational experiences and outcomes (Sacerdote, 2011). Among the numerous theoretical discussions about how peer effects operate, the tracking model is particularly relevant to the current study (Holmes, 1912). Specifically, based on the assumption that a student learns best when her own achievement level is close to what the teacher is teaching, the model suggests that students may benefit from a tracking system that groups students of similar achievement levels and allows instructors to tailor lessons to that level (e.g., Borman \& Hewes, 2002; Duflo, Dupas, \& Kremer, 2011; Hoxby \& Weingarth, 2005; Zimmer, 2003). For example, Hoxby and Weingarth (2005) found that students benefit from having more academically homogeneous peers, which the authors attributed to more targeted instruction. Similarly, Duflo et al. (2001) found that students at all levels of the initial achievement spectrum benefited from being tracked into classes by their prior achievement, and such benefits seem to be primarily driven by allowing teachers to more closely match instruction to students' needs. Under this theoretical framework, the presence of DE students could bring additional challenges to instruction due to the wider range of achievement levels and diverse needs of students. 
In addition to the indirect peer effects created through teaching practices and attention, DE students may also directly influence non-DE community college enrollees by changing the classroom achievement composition and the relative ranking of students. Since most states require students to meet eligibility criteria to be admitted to a DE program - such as acquiring teacher-written recommendations, meeting a minimum high school grade point average (GPA), or passing state-determined postsecondary assessments - students eligible to take college coursework through DE typically have higher academic performance levels than their non-DE community college student peers. ${ }^{2}$ Having high-achieving high school peers in the classroom may push the non-DE community college enrollees toward the lower end of the grade distribution. Lower ordinal rank may negatively influence self-perceived ability and confidence, which in turn could affect an individual's time investment in academic study and her educational decisions (Hoxby \& Weingarth, 2005; Marsh et al., 2008). Indeed, a number of recent studies conducted at the primary and secondary school level indicate that higher ordinal rank in a group, independent of actual achievement, has sizable positive impacts on test scores and confidence (Murphy \& Weinhardt, 2018), college-going (Elsner \& Isphording, 2017), health outcomes (Elsner \& Isphording, 2018), and adult earnings (Denning, Murphy \& Weinhardt, 2018). Such impacts exist throughout the entire rank distribution (Murphy \& Weinhardt, 2018).

The influence of relative rank in a classroom is likely to exist and may be even more pronounced in the postsecondary setting, where instructors commonly grade students on a curve. Moreover, minority and low-income students who are overrepresented in community colleges may be more heavily influenced by their classroom experience than other students, since such students on average have lower levels of confidence and a lower sense of belonging in the academic classroom setting to begin with (Freeman, Anderman, \& Jensen, 2007; Hoxby \& Avery, 2012; Ostrove \& Long, 2007; Strayhorn, 2008, 2018). Indeed, as noted just above, studies conducted at K-12

\footnotetext{
${ }^{2}$ In 2016, six states included minimum high school grade point average (GPA) as a criterion to be admitted to a dual enrollment program; 17 states required written permission or a recommendation from a teacher or school official; 25 states required DE candidates to meet course prerequisites set by the departments or institutions offering DE programs; and 24 states included other eligibility criteria, such as completion of certain high school courses or passing scores on state-determined high school or postsecondary assessments. For more detailed information, see Zinth (2016).
} 
schools have revealed strong heterogeneity in the influence of ordinal rank by individual characteristics (Murphy \& Weinhardt, 2018), where low-income students benefit substantially more from being in the top 25 th percentile in their class than their higher income peers. If similar patterns hold in the community college setting-which consists of large proportions of low-income, minority, and first-generation students - then it implies that the benefits of having a relatively higher rank in class for these students could be reduced as a result of the presence of high-achieving high school peers.

\subsection{The Current Study}

Our study builds on the peer effects literature and intends to advance understanding of the externalities of DE peers in two ways. First, while a growing number of studies have examined the impact of DE, they have exclusively focused on how participation in DE influences high school students' academic choices and performance. In contrast, the field has no rigorous evidence regarding the impact of DE peers on non-DE community college enrollees' outcomes. Given the current expansion of $\mathrm{DE}$ across the nation, it is critical for policymakers to understand whether having $\mathrm{DE}$ students in the college classroom serves to crowd out the limited resources available to non-DE community college enrollees who are already disproportionately from disadvantaged backgrounds. Our study fills this research gap by delivering the first quasiexperimental evidence on this issue.

Second, our study extends the general peer effects literature by approaching this topic in an under-examined setting. The majority of peer effects research has been conducted in the K-12 setting (e.g., Betts \& Zau, 2004; Boozer \& Cacciola, 2001; Burke \& Sass, 2013; Hoxby, 2000; Hoxby \& Weingarth, 2005; Imberman, Kugler \& Sacerdote, 2012; Lavy, Paserman \& Schlosser, 2011; Lefgren, 2004; Whitmore, 2005). While a growing number of studies have examined peer externalities at the postsecondary level, they have been conducted at military schools (e.g., Carrell, Fullerton, \& West, 2009; Lyle, 2007) and elite four-year universities (e.g., Ficano, 2012; Ost, 2010; Sacerdote, 2011; Zimmer, 2003). Given the substantial differences in student composition between an elite four-year college and an open-access institution, it is unclear whether results from these studies can be generalized to open-access colleges. The datasets we use contain transcript data from between 2012 and 2017 on all community college students from a 
large state community college system of over 20 colleges. Therefore, results from our study complement the existing literature by shedding light on the existence and extent of peer effects in the community college setting with strong external validity.

\section{Data and Setting}

\subsection{State Context in Dual Enrollment}

The state examined in this study mandates that all public secondary schools and all public two-year and four-year colleges participate in the statewide DE program. Specifically, each public secondary school is required to develop, in consultation with at least one partnering college, a set of college courses offered to eligible students, which enables high school students to take courses in high school and college simultaneously. In the state, ninth through 12th-grade students who have a high school GPA of 3.0 or above in the subject they wish to participate in through the DE program are eligible to do so. Although they are not required to develop partnerships with colleges, private secondary schools cannot deny eligible students from participating in DE. The state covers tuition for all DE coursework, associated fees, and materials for all public, chartered, and private high school students. DE primarily takes place during the fall and spring terms, with summer term enrollments accounting for just 10\% of total DE participation in 2016-17. The average DE participation rate in this state is $10 \%$, with noticeable enrollment gaps between White (11\%) and non-White students; the participation rate is $4 \%$ among Black students and $7 \%$ among Hispanic students, which is fairly consistent with overall participation rates and racial/ethnic gaps nationally. ${ }^{3}$

DE courses in this state may be offered at college campuses and high schools. To ensure the quality of DE experiences, the state mandates that all DE courses offered at a partnering college campus, whether they are delivered face-to-face or online, be the same as those included in that college's course catalog for college-level, nonremedial courses. Courses offered at the secondary school must follow the same course syllabus; employ

\footnotetext{
${ }^{3}$ Based on a recent report that analyzes data from the Civil Rights Data Collection on the 2015-2016 school year (Fink, 2018), the average national DE participation rate is $8 \%$; the rates are higher among White $(10 \%)$ and Asian (8\%) students, compared with Black (5\%) and Hispanic (6\%) students.
} 
the same learning outcomes; and use the same textbook, materials, and assessments as the equivalent college courses delivered on the college campus. In 2016-17, approximately one third of DE courses were taken on a college campus, and among these courses, approximately one quarter were offered by the state community college system (referred to as SCCS hereafter).

Figure 1 (above) shows the share of college students who were dual enrolled at the public two-and four-year institutions in the state each year between 2009 and 2016 in and reveals two important patterns. First, the proportion of DE students grew steadily during this period in both sectors, and the growth rate noticeably accelerated in more recent years. This is partly driven by a series of state policies implemented in the mid2010s to incentivize DE, including allowing seventh- and eighth-graders to participate in the program and increasing the number of high school equivalent credits per college credit. 4

Second, since community colleges account for $60 \%$ of all college campus DE enrollments, DE students represent a much larger percentage of community college enrollees than they do four-year enrollees. Moreover, the proportion of DE students has increased especially quickly at two-year institutions since 2014, further widening the gaps in the student population percentage accounted for by DE students in the two-year and four-year sectors. (For example, according to SCCS's annual report, the total DE enrollment grew from around 54,000 to 68,000 students between the 2015-16 and 201617 academic years.) In 2016, 18\% of total community college enrollments were DE students, compared with only $4 \%$ of students in the four-year sector. These patterns suggest that for current community college enrollees in SCCS, every five community college students includes one high school student, and the proportion may be even higher in the lower division coursework that is most popular among DE students. With the state and nationwide push for DE expansion, the heavy exposure to DE peers is likely to continue or even increase in the next few years, further highlighting the importance of understanding the impact of DE peers on the academic outcomes of non-DE community college enrollees.

\footnotetext{
${ }^{4}$ Since transportation is not covered by the program, approximately $70 \%$ of all the participants are still eleventh and twelfth graders, who are able to drive or take public transportation to the local colleges themselves.
} 


\subsection{Data and Key Measures}

We utilize administrative data from SCCS that includes approximately 386,000 students who enrolled in the system at any point between fall 2009 and summer 2017. We use the full dataset to describe the DE enrollments trend (Figure 1) but restrict the subsequent analyses to students enrolled in 2012 or later, as grades are missing in prior years. The dataset includes student demographic characteristics and transcript records from all courses taken by a student, including grades received, course section number, delivery method (face-to-face versus online), course subject, and whether the student took the course as an undergraduate student or as a high school student through DE. Each course section has an instructor identifier, which is linked to a separate instructor file that includes individual-level information (such as demographic characteristics) as well as instructor-by-term-level information (such as academic rank, highest degree earned, and teaching experiences).

DE status. We use student-by-course flags to indicate an individual's DE status in a particular course. Individuals contribute to the course-level DE count only for the terms they enroll as DE students and not after they matriculate as college students. For example, a high school student may take a college gateway course through a DE program in the fall of 2013 and then matriculate at a community college in the fall of 2014 . This student would serve as a source of treatment as a DE peer only during 2013. Approximately $30 \%$ of the gatekeeper course sections included in our analytical sample enrolled at least one DE student.

Outcome measures. To provide a comprehensive understanding of how exposure to DE students influences the academic outcomes of non-DE community college enrollees, we focus on both current course outcomes and subsequent course enrollment. The analyses on current course outcomes include the probability of passing the current course unconditional on completion and persisting to the end of the course, as well as the average end-of-course GPA among those who persisted to the end of the course. For subsequent outcomes, we examine the likelihood of repeating the same course and enrolling in a different course in the same subject as the current course. ${ }^{5}$

\footnotetext{
${ }^{5}$ We also conduct analyses using next course performance in the same subject as the gateway course (passing rate and the course grade) as outcomes conditional on persisting to another course in the subject.
} 
Our analysis focuses on estimating the effect of DE peers on non-DE community college students' academic outcomes in their gateway courses. Gateway courses are a set of courses that community college students must take in order to progress through their chosen major. For English, Composition I and II are generally required for most programs. Math requirements and the flexibility of those requirements differ by major and program. Common math gateway courses include College Algebra, Trigonometry, Statistics, Precalculus, and Mathematical Foundations. Math and English gateway courses are the most popular courses for DE students. Specifically, DE participation accounted for $15 \%$ of the total enrollment in these gateway courses during the period of this study, compared with $6 \%$ in other courses. High demand in gateway courses leads to a multiplicity of sections under each course, thereby providing substantial within-course variation in students' exposure to DE peers that is critical to our identification strategy. Figure 2A shows the distribution of the proportion of DE students across all course sections in gateway courses. Among the 18,512 course sections, the proportion of DE students ranged between $0 \%$ and $100 \%$.

\subsection{Sample and Summary Statistics}

We make three key sample restrictions to ensure that our analytical sample is representative of a typical community college student. First, we exclude course sections that were offered at local high schools and thus had DE students only, which accounts for roughly $7 \%$ of all sections shown in Figure 2, Panel A. Second, another $18 \%$ of the sections had relatively high concentrations of DE students. These instances seem to be primarily in online English classes offered at a handful of community colleges and might have been purposefully designed for high school students. To avoid biasing our estimates with a small set of specially designed classes with exceptionally high concentrations of DE students, we drop these sections from our course sample. ${ }^{6}$

with next-course fixed effects in addition to individual and college-by-course fixed effects. However, given the limited percentage of students with variation in the percentage of DE students in courses taken in the same term, adding next-course fixed effects, conditional on enrollment in the subsequent course, substantially reduces that variation, undermining the individual fixed effects approach. Due to the concern of overfitting, we exclude the next-course fixed effects analyses from the paper.

${ }^{6}$ We conduct a number of robustness checks with different restriction criteria (such as dropping only the top $10 \%$ instead of the top $25 \%$ of the sections with the largest proportions of DE students), and the results are fairly consistent. 
Figure 2

Raw and Adjusted Distributions of the Percentage of DE Students in Math and English Gateway Course Sections

Panel A. Raw Percentage of Dual Enrollment Students per Course Section

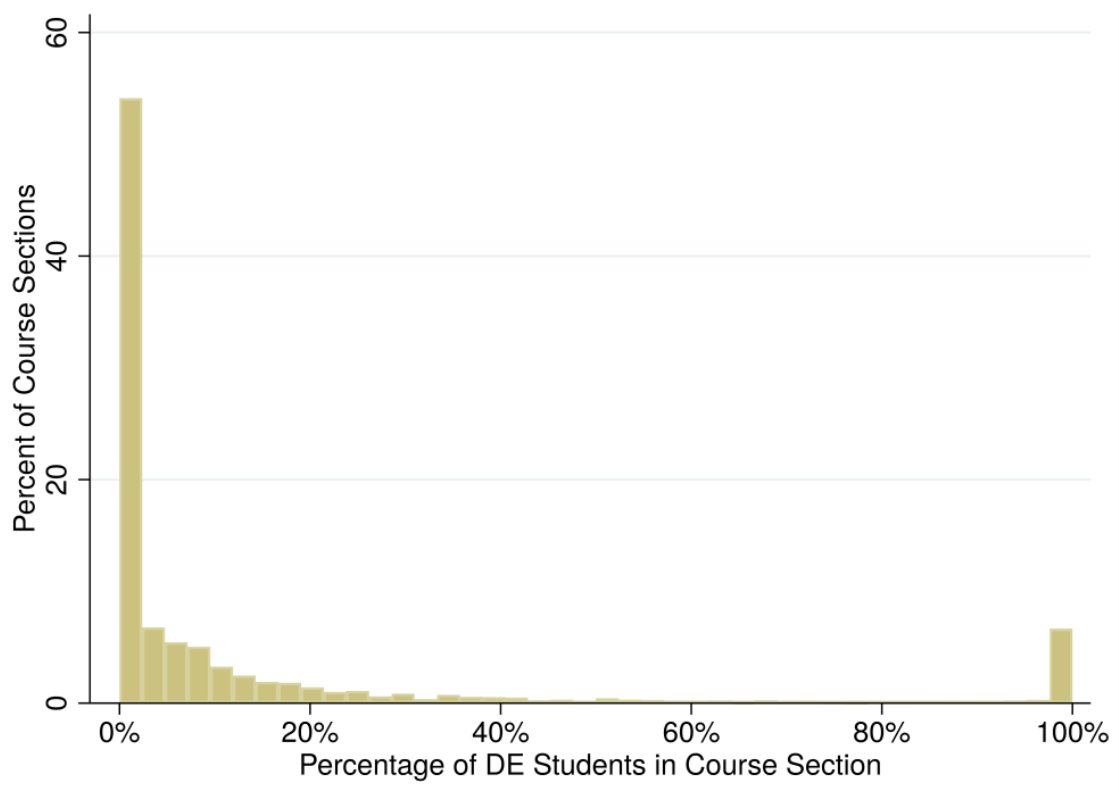

Panel B. Adjusted Percentage of Dual Enrollment Students per Course Section

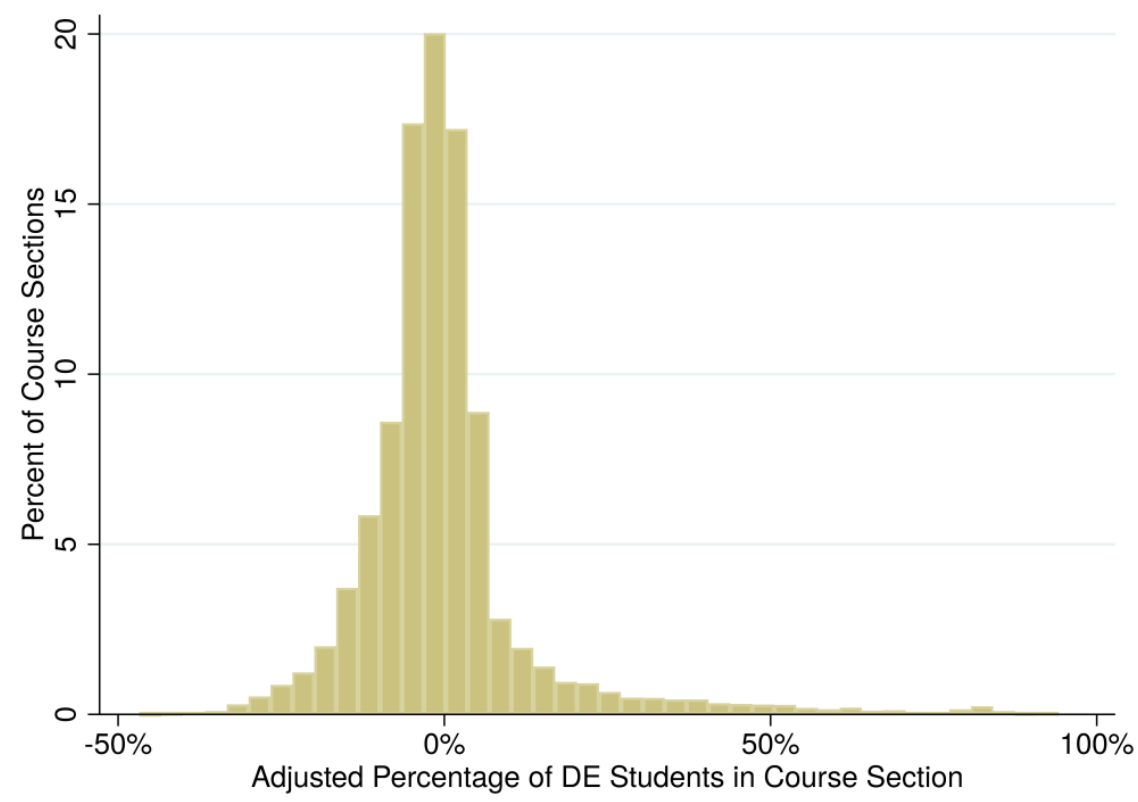

Note. The sample includes all gateway courses between fall of 2012 and summer of 2017. 
Third, approximately $2 \%$ of the students enrolled in gateway courses in our analytical sample appear as DE students in our sample first and later officially enrolled as non-DE community college students after they graduated from high school. Due to their own prior DE experiences, these students may have responded to DE peers differently than other community college students who never had DE experiences. In addition, as shown in Table 1, comparisons between community college students with or without prior DE experiences suggest that those with DE experiences (column 2, referred to as "ever-DE" hereafter) were substantially different from the majority of community college students without DE experiences (column 3, referred to as "never-DE"). For example, ever-DE college students were more likely to be younger, female, White, and in-district residents than their never-DE counterparts. They also had higher GPAs in the first term at SCCS and higher completion rates in associate degrees. ${ }^{7}$ Furthermore, as shown in Figure 3 , which presents the distribution of grades earned by ever- and never-DE students, everDE students were much more likely to attain higher grades in their gateway courses than never-DE students. In view of the noticeable differences between the small proportion of ever-DE (yet non-DE) community college students and the rest of the non-DE community college students with no DE experiences, we use the ever-DE students in calculating the treatment variable while they enrolled in the DE program and do not include them in our non-DE community college enrollee sample when analyzing the effects of DE peers on non-DE community college students. ${ }^{8}$

Our final analytic sample contains 13,897 course sections with an average of $2 \%$ of DE students per section and a standard deviation of 3 percentage points. Collectively, these sections include 264,716 total class enrollments by 8,000 DE students and 180,010 non-DE community college enrollees.

\footnotetext{
${ }^{7}$ We merge the college administrative data with National Student Clearinghouse data that contain information about awards obtained outside of the state. Therefore, degree attainment information presented in Table 1 includes credentials earned at institutions either within or outside the state.

${ }^{8}$ Our robustness check indicates that including former DE students, who later enrolled in community colleges, does not change our results.
} 
Table 1

Summary Statistics at the Student Level (Fall 2012-Summer 2017)

\begin{tabular}{lccc}
\hline & \multicolumn{3}{c}{ Status at Community Colleges } \\
\cline { 2 - 4 } & Exclusively DE & Ever DE & Never DE \\
\hline Observations & 4,120 & 3,858 & 180,010 \\
Demographic characteristics & & & \\
Female & $67 \%$ & $70 \%$ & $57 \%$ \\
White & $81 \%$ & $84 \%$ & $69 \%$ \\
Black & $7 \%$ & $6 \%$ & $17 \%$ \\
Hispanic & $3 \%$ & $4 \%$ & $4 \%$ \\
Other races/ethnicities & $13 \%$ & $13 \%$ & $13 \%$ \\
In-district resident & $37 \%$ & $43 \%$ & $24 \%$ \\
Out-of-district resident & $1 \%$ & $2 \%$ & $6 \%$ \\
In-state resident & $77 \%$ & $76 \%$ & $80 \%$ \\
Disabled & $5 \%$ & $6 \%$ & $11 \%$ \\
Entered SCCS in fall & & $62 \%$ & $61 \%$ \\
Age at college entry & 19 & 19 & 24 \\
Placed in remedial course & & $45 \%$ & $38 \%$ \\
Intention declared at college entry & & & \\
Recreation & $15 \%$ & $27 \%$ & $6 \%$ \\
Skills enhancement & $2 \%$ & $5 \%$ & $9 \%$ \\
Transfer from SCCS to 4-year college & $7 \%$ & $13 \%$ & $12 \%$ \\
Earn community college credentials & $23 \%$ & $43 \%$ & $69 \%$ \\
Earn a bachelor's degree & $14 \%$ & $17 \%$ & $12 \%$ \\
Missing intent & $76 \%$ & $63 \%$ & $22 \%$ \\
College performance and degree outcomes & & & \\
College credits earned in Term 1 & 6.6 & 5.5 & $16 \%$ \\
GPA in Term 1 & 3.16 & 3.05 & $14 \%$ \\
Ever earned a certificate & $30 \%$ & $22 \%$ & \\
Ever earned associate degree & $28 \%$ & $18 \%$ & \\
Ever earned bachelor's degree & & & \\
Missing NSC data (missing coverage for & $25 \%$ & $19 \%$ & \\
out of state degree attainment) & & & \\
\hline
\end{tabular}

Note. Data include all students enrolled in any gateway courses between fall of 2012 and summer of 2017 in which the classroom population was $12 \%$ or less DE students. 
Figure 3

Grade Point Average Distribution for All Gateway Courses

Among Ever-DE and Never-DE Community College Students

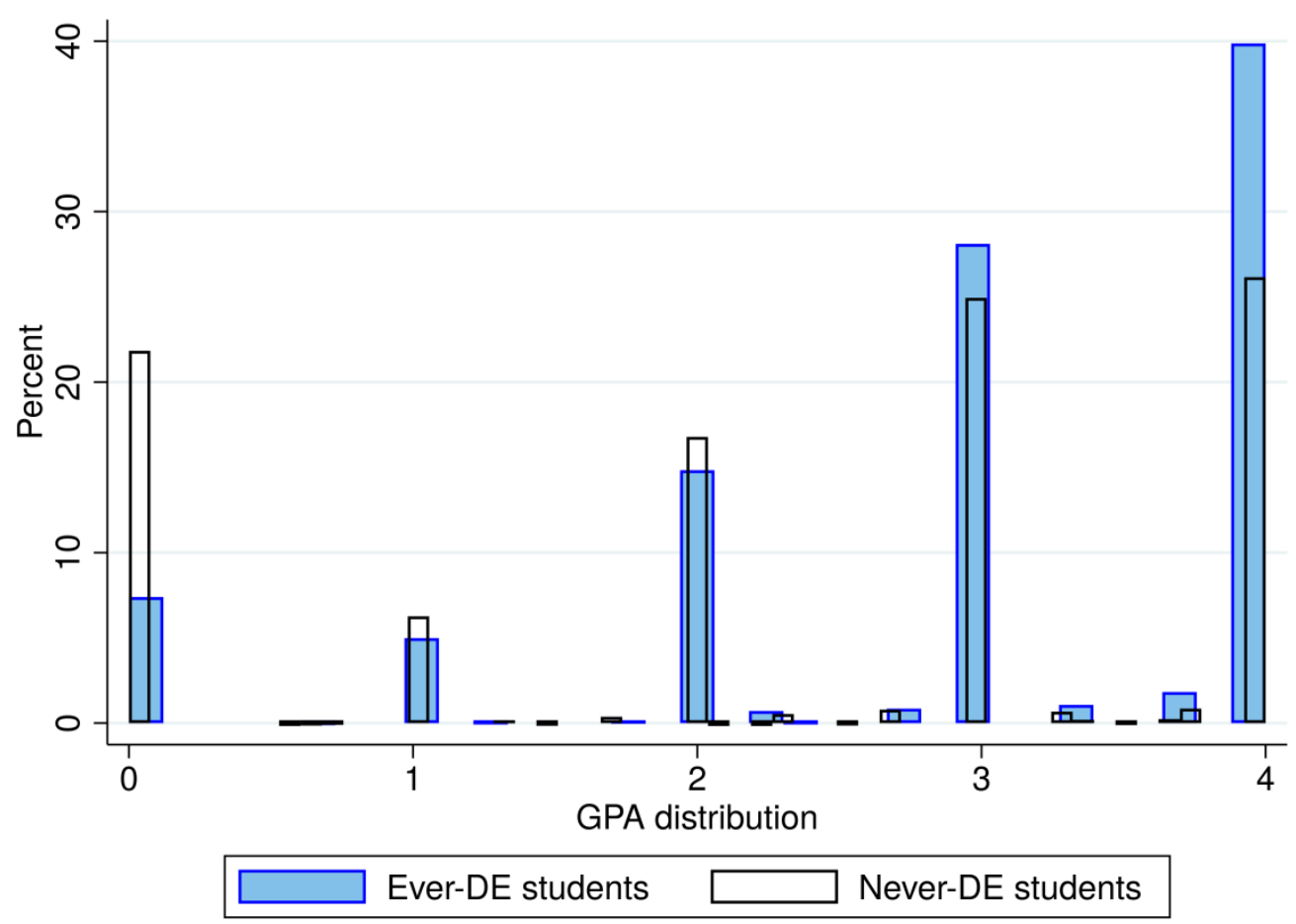

Note. The sample includes all gateway course grades earned between fall of 2012 and summer of 2017 in which the classroom population was $12 \%$ or less DE students.

\section{Empirical Model}

Our identification for current course outcomes relates a community college enrollee $i$ 's exposure to DE students in math and English gateway courses on her course performance in section $s$ of course $c$ in subject $f$ in term $t$ at campus $k$ :

$$
Y_{\text {iscftk }}=a+\beta \% D E_{\text {scftk }}+X_{\text {scftk }}+I_{\text {scftk }}+\delta_{\text {cfk }}+\sigma_{\mathrm{i}}+\rho_{\mathrm{t}}+\mu_{\text {iscftk }}
$$

The key variable of interest, $\% D E$, represents the percentage of $\mathrm{DE}$ peers in a specific course section, calculated as the total number of DE students in a section divided by the total enrollment in that section minus one. Given that the average class size per section is 23 students, where $2 \%$ are DE students, a one percentage point increase in DE 
peers would mean adding 0.4 more DE students to an average classroom. To make it easier to interpret, we multiply our key variable of interest by 10 , so that it ranges from 0 to 10 and allows us to interpret the results as a $10 \%$ increase in DE peers or an approximate equivalent of adding two more DE students into an average classroom of 23 students. Since we are interested in estimating the effect of having a higher proportion of DE peers and not the effect of demographic composition changes as a result of more DE peers, $X_{\text {scftk }}$ further controls for demographic composition in a section. In a separate robustness check, we exclude $X_{\text {scttk }}$ from our model, and the results are fairly consistent. $I_{\text {sctik }}$ is a vector that includes course-section-level information (e.g., the number of total enrollments in the course section, whether the course section is delivered online or faceto-face, etc.) and instructor characteristics such as gender, age, race/ethnicity, highest degree earned, appointment status (part-time versus full-time), tenure status (adjunct, tenure-track, and tenured), and rank (full, associate, or assistant professor). Finally, $\delta_{\text {cfk }}$ and $\rho_{\mathrm{t}}$ control for college-course and calendar term fixed effects, respectively.

The remaining source of selection after controlling for course-section level attributes, college-course fixed effects, and calendar term fixed effects is college students' and college instructors' differential sorting into sections with different proportions of DE peers. For example, DE students might be more likely to opt into sections offered during certain days at certain times, which may also be more popular among some subgroups of college students. We directly explore the extent of this selection in two ways: First, we examine whether students self-select themselves into sections with different percentages of DE students. We test whether observable characteristics of a current college enrollee, such as gender and race, are correlated with the proportion of DE peers she is exposed to after controlling for section-level attributes as well as college-course and term fixed effects. The student-course-level results presented in Table 2 suggest that the exposure to DE peers seems higher for community college students from certain subgroups, namely White students, students who enrolled part-time in their initial term, students who intended to receive an associate degree or certificate as their terminal degree, students placed into remedial mathematics education, and students who were not in college for the first time. To address possible selection bias due to student sorting across sections, we further include student individual fixed effects 
$\left(\sigma_{\mathrm{i}}\right)$ into the model, thus controlling for any unobservable student-level characteristics that are constant across courses.

Table 2

Predictors of Exposure to Dual Enrolled Students

\begin{tabular}{llc}
\hline Individual characteristics & \multicolumn{2}{c}{ Percentage of DE } \\
\hline Female & 0.002 & {$[0.002]$} \\
Race & & \\
$\quad$ Black & $-0.006^{* * *}$ & {$[0.001]$} \\
$\quad$ Hispanic & -0.007 & {$[0.005]$} \\
$\quad$ Other & $-0.008^{* * *}$ & {$[0.001]$} \\
Full-time first term & $-0.007^{* * *}$ & {$[0.002]$} \\
Percent with BA intent & 0.001 & {$[0.002]$} \\
Percent with community college degree intent & $0.013^{* * *}$ & {$[0.003]$} \\
In-district resident & -0.002 & {$[0.003]$} \\
Credits enrolled this term & $0.003^{* * *}$ & {$[0.001]$} \\
Age during course & $0.001^{* * *}$ & {$[0.000]$} \\
Started in fall & $0.003^{* *}$ & {$[0.001]$} \\
Placed in remedial English & -0.002 & {$[0.002]$} \\
Placed in remedial math & $0.006^{* * *}$ & {$[0.002]$} \\
First term enrolled & $-0.000^{* *}$ & {$[0.000]$} \\
High school graduation year & -0.000 & {$[0.000]$} \\
First time in college & $-0.004^{* *}$ & {$[0.002]$} \\
Credits earned last term & $0.001^{* * *}$ & {$[0.000]$} \\
College credits earned last term & $-0.000^{* *}$ & {$[0.000]$} \\
Credits earned last term in subject & $-0.000^{* *}$ & {$[0.000]$} \\
& & \\
Observations & & 264,716 \\
$R^{2}$ & & 0.352 \\
\hline
\end{tabular}

Note. Robust standard errors are in brackets and are clustered at the course-by-term and student levels. All regressions control for course section and instructor characteristics and contain college-course and term fixed effects. Singletons are included in the regressions. Results are almost identical when excluding singletons from the estimation.

${ }^{*} p<.1 . * * p<.05 . * * * p<.01$.

Second, in addition to student sorting, another potential threat to our identification strategy is that instructors with certain characteristics might be more likely to teach sections that consist of a larger proportion of DE students. We therefore conduct a balance test at the course-section level, where we regress the proportion of DE students 
on the observable characteristics of the instructor teaching that section. We also control for other section-level attributes as well as college-course fixed effects and term fixed effects. Results from this exploration are presented in Appendix Table A1. Except for a handful of cases, we do not find any consistent correlation between the proportions of $\mathrm{DE}$ students in a course section with either section-level attributes or instructor characteristics, indicating that course sections with a higher concentration of DE students are fairly comparable to those with a lower proportion of DE students in terms of observable section-level characteristics.

Once we include individual fixed effects $\left(\sigma_{\mathrm{i}}\right)$ into the model, Equation 1 draws on two sources of variation. The first is within-individual variation, in which a college student typically takes multiple gateway courses and each gateway section may consist of a different proportion of DE peers. Among the 92,523 students who took more than one gateway course, $64 \%$ had variation in the percentage of DE peers they were exposed to.

The second is the variation in the percentage of DE students across sections of the same course. Since the model includes college-course fixed effects, only courses with between-section variation in the proportion of DE students would contribute to the estimate of $\beta$. As shown in Figure 2, Panel A, there was substantial variation in the proportion of DE students across course sections. Specifically, approximately $64 \%$ of the courses had within-course, between-section variation in the proportion of students who were dual enrolled. Figure 2, Panel B further shows the distribution after adjusting for the course and term fixed effects. The residuals follow an approximately normal distribution. These distributions, therefore, support the use of college-course fixed effects. 


\section{Empirical Results}

\subsection{Main Findings}

Table 3 presents the estimated effect of increasing the proportion of DE students in a course section by 10 percentage points on non-DE community college students' current course outcomes. As mentioned before, a 10 percentage point increase in DE peers is similar to adding two DE students to an average class of 23 students. We first explore three main outcome measures (columns 1-3): (1) successfully completing a course with a passing grade (versus either failing or withdrawing from the course), (2) persisting to the end of the course (versus withdrawing), and (3) the final course grade on a 4.0 scale, conditional on persisting to the end of the course.

Table 3 Effect of DE Peers on Non-DE Community College Students' Current Course Outcomes

\begin{tabular}{lccc}
\hline Outcomes & Passed current course & $\begin{array}{c}\text { Persisted to end of } \\
\text { course }\end{array}$ & GPA \\
\hline Percentage of DE peers & $-0.019 * * *$ & $-0.010^{*}$ & $-0.055^{* * *}$ \\
& {$[0.006]$} & {$[0.005]$} & {$[0.018]$} \\
Sample mean & 0.676 & 0.868 & 2.293 \\
& & & 229,634 \\
Observations & 264,716 & 264,716 & 0.862 \\
\hline
\end{tabular}

Note. Robust standard errors are in brackets and are clustered at the course-by-term and student levels. All regressions have a full set of covariates and include current college-course, student, and term fixed effects. Singletons are included in the regressions. Results are almost identical when excluding singletons from the estimation.

${ }^{*} p<.1 .{ }^{*} p<.05 . * * * p<.01$.

Overall, within the same course at a community college, having a higher proportion of DE peers in a section had a small but significant negative effect on non-DE community college enrollees in terms of all three outcome measures. Specifically, a nonDE college enrollee was 2 percentage points less likely to pass a course for every 10 percentage point increase in DE peers. Given that the overall course pass rate was $68 \%$, this 2 percentage point decline translates to a pass rate reduction of approximately $3 \%$. The negative effect of DE peers on overall course completion is driven by both a lower 
likelihood of persisting to the end of the course (the course persistence rate decreased by 1 percentage point for every 10 percentage point increase in DE peers) and a lower GPA among those who persisted to the end of the course (the average GPA was 0.06 lower for every 10 percentage point increase in DE peers).

In view of the negative effect of $\mathrm{DE}$ peers on non-DE community college enrollees' current course outcomes, we next examine whether these negative effects led to any effect on two downstream outcomes: (1) the likelihood of repeating the same course (course repetition) and (2) the likelihood of enrolling in a new course in the same subject area (subject persistence). The results presented in Table 4 indicate that a 10 percentage point increase in DE peers in a gateway course increased the likelihood that a non-DE community college student repeated that course by 1.3 percentage points. (Given that the average rate of course repetition was $12.5 \%$, an increase of 1.3 percentage points is equivalent to a 10 percent increase.) This is not surprising given that students exposed to more DE peers were less likely to pass the current course, and it points to specific costs accrued for non-DE community college enrollees as a result of greater exposure to DE peers. Once we exclude repeated courses, higher exposure to DE peers is also associated with lower rates of subject persistence; each 10 percentage point increase in DE peers is associated with a 1 percentage point decrease (or 3\% reduction from the average) in enrolling in a new course in the corresponding subject area.

Table 4

Effect of DE Peers on Non-DE Community College Students' Next Course Outcomes

\begin{tabular}{lcc}
\hline & $\begin{array}{c}\text { Repeated } \\
\text { same course }\end{array}$ & $\begin{array}{c}\text { Enrolled in different course } \\
\text { in same subject }\end{array}$ \\
\hline Percentage of DE peers & $0.013^{* *}$ & $-0.009^{* *}$ \\
& {$[0.005]$} & {$[0.004]$} \\
Sample mean & 0.125 & 0.330 \\
& & \\
Observations & 264,716 & 264,716 \\
$R^{2}$ & 0.570 & 0.843 \\
\hline
\end{tabular}

Note. Robust standard errors are in brackets and are clustered at the course-by-term and student levels. All regressions have a full set of covariates and include current college-course, student, and term fixed effects. Singletons are included in all the regressions. Results are almost identical when excluding singletons from the estimation.

${ }^{*} p<.1 . * * p<.05 . * * * p<.01$. 


\subsection{Heterogeneity by Student Prior Academic Performance}

Our results so far suggest that an increase in the proportion of DE students in a particular course section negatively affected non-DE community college enrollees' current and downstream outcomes. The peer effect literature has shown evidence that peer externalities have nonlinear impacts on students with different academic proficiencies (e.g., Duflo et al., 2011; Hoxby \& Weingarth, 2005; Lavy, Silva \& Weinhardt, 2009). Therefore, we further explore whether the negative effect of DE peers on non-DE community college students varies by college students' prior academic performance. Specifically, we divide college students in our sample in half based on the median of their GPA in college-level, non-gateway courses in their first term of college. The first half includes students with a first-term GPA below approximately 3.0, and the second half includes those with a first-term GPA equal to or higher than 3.0. (It is worth noting that this analysis excludes students who did not enroll in college-level, nongateway courses in the first term. Yet, the results presented in Appendix Table A2 indicate that the estimated effect of DE peers is fairly consistent between our analytical sample and the reduced sample that excludes students without valid first-term GPA.)

Table 5 presents the estimated heterogeneous effect of having a greater proportion of DE peers on non-DE community college students' current course outcomes. The results indicate that the negative effects on current course performance affected all nonDE community college enrollees regardless of their prior performance. For lower achieving students, each 10 percentage point increase in DE peers lowered the likelihood of passing the current course by 1.8 percentage points. Greater exposure to DE peers also negatively affected lower achieving students' course persistence rates (there was a 2.1 percentage point reduction per 10 percentage point increase in DE peers), suggesting that the negative impact on passing was primarily driven by the greater probability of withdrawing from the course. Similar to lower achieving students, higher achieving students' probability of passing the current course was also negatively influenced by an increase in DE peers. The lower passing rate was in this case primarily due to lower course grades (though the coefficient is not statistically significant), and not a result of a lower course completion rate. 


\section{Table 5}

Heterogeneous Effect of Dual Enrollment Peers on

Non-DE Community College Students' Current Course Outcomes, by Prior GPA

\begin{tabular}{lccc}
\hline Outcomes & $\begin{array}{c}\text { Passed } \\
\text { current course }\end{array}$ & $\begin{array}{c}\text { Persisted to } \\
\text { end of course }\end{array}$ & GPA \\
\hline Percentage of DE peers & $-0.018^{* *}$ & $-0.021^{* *}$ & -0.046 \\
& {$[0.008]$} & {$[0.008]$} & {$[0.032]$} \\
Top 50 percentile GPA * \% of DE peers & 0.001 & $0.017^{* *}$ & -0.015 \\
& {$[0.010]$} & {$[0.008]$} & {$[0.043]$} \\
Observations & 157,442 & 157,442 & 140,467 \\
$R^{2}$ & 0.755 & 0.673 & 0.838 \\
\hline
\end{tabular}

Note: Robust standard errors are in brackets and are clustered at the course-by-term and student levels. All regressions have a full set of covariates and include current college-course, student, and term fixed effects. Singletons are included in the regressions. Results are almost identical when excluding singletons from the estimation.

${ }^{*} p<.1 .{ }^{* *} p<.05 .{ }^{* * *} p<.01$.

Table 6 presents the heterogeneous effect of DE peers on non-DE community college students' subsequent outcomes. Column 1 shows that the negative impact of DE peers on current course outcome led to an increase in course repetition among both lower and higher achieving students. In addition, higher achieving non-DE community college students were less likely to persist in the same subject of the gateway course in which they shared the classroom with DE peers. Each 10 percentage point increase in DE peers in the current gateway course reduced the subject persistent rate by 2.9 percentage points.

Table 6

Heterogeneous Effect of Dual Enrollment Peers on Non-DE Community College Students' Next Course Outcomes, by Prior GPA

\begin{tabular}{lcc}
\hline Outcomes & $\begin{array}{c}\text { Repeated } \\
\text { same course }\end{array}$ & $\begin{array}{c}\text { Enrolled in different } \\
\text { course in same subject }\end{array}$ \\
\hline Percentage of DE peers & $0.026 * *$ & 0.006 \\
& {$[0.011]$} & {$[0.007]$} \\
Top 50 Percentile GPA * \% of DE peers & -0.016 & $-0.029 * *$ \\
& {$[0.013]$} & $10.012]$ \\
Observations & 157,442 & 157,442 \\
$R^{2}$ & 0.555 & 0.837 \\
\hline
\end{tabular}

Note. Robust standard errors are in brackets and are clustered at the course-by-term and student levels. All regressions have a full set of covariates and include current college-course, student, and term fixed effects. Singletons are included in the regressions. Results are almost identical when excluding singletons from the estimation.

${ }^{*} p<.1 .{ }^{*} p<.05 . * * * p<.01$. 
The subgroup results show that having a higher proportion of DE students negatively affected the current course outcomes and course repetition rates of non-DE community college students across all achievement distributions. Additionally, higher achieving non-DE community college students had a low persistence rate in the gateway course sections in which they enrolled with more DE peers. The wider range of achievement levels in the classroom may indeed have made it more difficult for instructors to provide as much support for non-DE community college enrollees. And since grading on a curve is a common practice in postsecondary courses, having a higher number of high-achieving DE students could have resulted in non-DE community college students being pushed down in the grade distribution. The negative effect on current outcomes led to increased course repetition and lower subject persistence.

\subsection{Robustness Checks}

This section outlines the results of sensitivity tests for various sample restrictions, controls, and treatment effects. First, to estimate the effect of having DE peers on a typical non-DE community college student, we limit our sample to course sections in which DE students made up less than $12 \%$ of total enrollment. We first test for the sensitivity of including courses in which DE students made up between $12 \%$ and $56 \%$ of total enrollment, which enables the coverage of up to $90 \%$ of the course sections. Panel A of Table 7 shows that while the magnitude of the effect of DE students on non-DE community college students' current and downstream outcomes was much smaller with the inclusion of courses with a high percentage of DE students, the direction and statistical significance remains the same as in Table 3 and Table 4.

Second, we have thus far limited our analytical sample to community college students without any DE experience as high school students, as they had very different demographic and academic characteristics compared to those students with DE experience. Table 7, Panel B, shows results for an alternative model adding former DE students who later became community college students to test for the sensitivity of this restriction. Our results are robust to this change.

Third, our models have controlled for the characteristics of both DE and non-DE students in the same section. We are primarily interested in estimating the peer effect through having a larger proportion of peers with high school student status and minimal 
college experiences, instead of the effect of having more students with certain characteristics in terms of race/ethnicity, age, gender, and academic performance. Table 1 shows that DE students were more likely to be younger and female, and to have had higher academic achievement than non-DE community college students. These characteristics may provide some additional potential mechanisms for DE students to have influenced non-DE community college students. Panel C applies a less restrictive model by excluding controls for the individual attributes of DE students. The results are very similar to our main model in Tables 3 and 4 .

Finally, we have focused on the treatment effect of having a 10 percentage point higher exposure to DE peers. This definition is helpful to present the results in a way that is easy to interpret. In Panels D and E, we depart from the 10 percentage point exposure and use alternative definitions of the treatment effect. Panel D shows the effects of simply being in a course section with any DE peers on selected current and next course outcomes using a binary indicator. Panel D of Table 7 indicates that when replacing our main treatment specification with a binary indicator of having any DE peers in the course 
Table 7

Effects Using Different Treatment Effect Definition and Specifications

\begin{tabular}{|c|c|c|c|c|c|}
\hline & $\begin{array}{l}\text { Passed } \\
\text { current } \\
\text { course }\end{array}$ & $\begin{array}{l}\text { Persisted to } \\
\text { end of course }\end{array}$ & GPA & $\begin{array}{c}\text { Repeated } \\
\text { same course }\end{array}$ & $\begin{array}{l}\text { Enrolled in } \\
\text { different } \\
\text { course in } \\
\text { same subject }\end{array}$ \\
\hline \multicolumn{6}{|c|}{ Panel A. Include courses with DE\% < 56\% } \\
\hline Percentage of DE peers & $\begin{array}{l}-0.005^{* *} \\
{[0.002]}\end{array}$ & $\begin{array}{l}-0.002 \\
{[0.002]}\end{array}$ & $\begin{array}{l}-0.013^{*} \\
{[0.006]}\end{array}$ & $\begin{array}{l}0.006 * * \\
{[0.002]}\end{array}$ & $\begin{array}{l}-0.004 * * \\
{[0.002]}\end{array}$ \\
\hline Observations & 305,974 & 305,974 & 265,938 & 305,974 & 305,974 \\
\hline$R^{2}$ & 0.768 & 0.687 & 0.845 & 0.536 & 0.822 \\
\hline \multicolumn{6}{|c|}{ Panel B. Include former DE students } \\
\hline Percentage of DE peers & $\begin{array}{l}-0.020 * * * \\
{[0.006]}\end{array}$ & $\begin{array}{l}-0.010^{*} \\
{[0.005]}\end{array}$ & $\begin{array}{l}-0.057 * * * \\
{[0.018]}\end{array}$ & $\begin{array}{c}0.014 * * \\
{[0.006]}\end{array}$ & $\begin{array}{l}-0.009 * * \\
{[0.004]}\end{array}$ \\
\hline Observations & 269,635 & 269,635 & 234,109 & 269,635 & 269,635 \\
\hline$R^{2}$ & 0.792 & 0.716 & 0.863 & 0.571 & 0.844 \\
\hline \multicolumn{6}{|c|}{ Panel C. No controls for DE peers' characteristics } \\
\hline Percentage of DE peers & $\begin{array}{c}-0.021 * * * \\
{[0.006]}\end{array}$ & $\begin{array}{l}-0.009 \\
{[0.006]}\end{array}$ & $\begin{array}{c}-0.066 * * * \\
{[0.018]}\end{array}$ & $\begin{array}{l}0.016 * * * \\
{[0.006]}\end{array}$ & $\begin{array}{l}-0.006 \\
{[0.005]}\end{array}$ \\
\hline Observations & 264,716 & 264,716 & 229,634 & 264,716 & 264,716 \\
\hline$R^{2}$ & 0.791 & 0.716 & 0.862 & 0.570 & 0.843 \\
\hline \multicolumn{6}{|c|}{ Panel D. Treatment = any DE peers } \\
\hline Having any DE peers & $\begin{array}{l}-0.011 * * \\
{[0.004]}\end{array}$ & $\begin{array}{l}-0.006 \\
{[0.003]}\end{array}$ & $\begin{array}{l}-0.030 * * \\
{[0.013]}\end{array}$ & $\begin{array}{c}0.007 \\
{[0.005]}\end{array}$ & $\begin{array}{l}-0.005 \\
{[0.003]}\end{array}$ \\
\hline Observations & 264,716 & 264,716 & 229,634 & 264,716 & 264,716 \\
\hline$R^{2}$ & 0.791 & 0.716 & 0.862 & 0.570 & 0.843 \\
\hline \multicolumn{6}{|c|}{ Panel E. Treatment in DE\% } \\
\hline $0<\mathrm{DE}$ percentage $\leq 4.35 \%$ & $\begin{array}{l}-0.006 \\
{[0.006]}\end{array}$ & $\begin{array}{l}-0.000 \\
{[0.005]}\end{array}$ & $\begin{array}{l}-0.021 \\
{[0.015]}\end{array}$ & $\begin{array}{c}0.004 \\
{[0.006]}\end{array}$ & $\begin{array}{l}-0.002 \\
{[0.005]}\end{array}$ \\
\hline $4.35 \%<\mathrm{DE}$ percentage $\leq 7.41 \%$ & $\begin{array}{c}-0.015^{* * *} \\
{[0.005]}\end{array}$ & $\begin{array}{l}-0.010 * \\
{[0.005]}\end{array}$ & $\begin{array}{l}-0.032 \\
{[0.019]}\end{array}$ & $\begin{array}{c}0.008 \\
{[0.005]}\end{array}$ & $\begin{array}{l}-0.002 \\
{[0.003]}\end{array}$ \\
\hline DE percentage $>7.41 \%$ & $\begin{array}{l}-0.013^{*} \\
{[0.007]}\end{array}$ & $\begin{array}{l}-0.008 \\
{[0.006]}\end{array}$ & $\begin{array}{l}-0.040 * * \\
{[0.018]}\end{array}$ & $\begin{array}{c}0.010 \\
{[0.007]}\end{array}$ & $\begin{array}{l}-0.012^{*} \\
{[0.006]}\end{array}$ \\
\hline Observations & 264,716 & 264,716 & 229,634 & 264,716 & 264,716 \\
\hline$R^{2}$ & 0.791 & 0.716 & 0.862 & 0.570 & 0.843 \\
\hline
\end{tabular}

Note. Robust standard errors are in brackets and are clustered at the course-by-term and student levels. All regressions have a full set of covariates and include current college-course, student, and term fixed effects. Regression in Panel A control only for individual characteristics of non-DE students and not for DE students. Singletons are included in the regressions. Results are almost identical when excluding singletons from the estimation.

${ }^{*} p<.1 .{ }^{* *} p<.05 .{ }^{* * *} p<.01$. 
section, the results are consistent with the results from using a continuous treatment variable, though they are less precisely estimated.

In Panel E, we test for any nonlinear effect of DE peers based on the percentage of DE peers in the course section. To do so, we generate three binary variables according to the tertile of the percentage of students in a course who were dual enrolled in our sample. This specification is also helpful to see whether there is a tipping point when DE peers start or stop having an effect.

Panel E indicates that there is nonlinearity in how exposure to DE peers affected non-DE community college students. A third of the non-DE community college students exposed to DE peers were in courses with less than $4.35 \%$ DE peers, and this level of exposure did not significantly affect them. As the DE percentage goes above $4.35 \%$, the negative impact of DE peers seems to be consistent and linear. Again, both Panels D and $\mathrm{E}$ in Table 7 are consistent with the main analysis.

\section{Discussion and Conclusion}

The rapid growth in DE in recent years has drawn much attention to the impact of these programs. In this paper, we empirically investigate whether exposure to greater proportions of DE peers in gateway math and English course sections influences non-DE community college enrollees' own achievement, as measured by their current course outcomes and subsequent course enrollments. To do so, we exploit the variations in the proportion of DE students across classrooms within a specific course and combine the course fixed effects model with individual fixed effects that control for sorting that is fixed at the course and student level. Our results suggest that DE peers have statistically significant negative effects on their classmates' current course outcomes, as measured by the probability of passing the course, course persistence, and course grades.

To explore how these negative effects on current course performance may influence downstream outcomes, we further examine the effect of DE peers in gateway math and English classes on non-DE community college enrollees' likelihood of repeating the same course and taking a new course in the same subject area. We find that

being exposed to a higher percentage of DE peers in gateway courses is associated with a 
higher likelihood of course repetition for non-DE community college enrollees. This is not surprising given the lower course pass rates in gateway course sections with higher proportions of DE peers, and it points to the tangible and intangible costs imposed on non-DE community college students as a result of greater exposure to DE peers. Furthermore, we find a negative effect of DE peers on non-DE community college student enrollment in a subsequent class in the same subject area.

Our heterogeneity analyses by student first-term academic achievement indicate that the negative effects of DE peers appear to influence non-DE community college students across the entire academic performance distribution. Finally, our nonlinearity test by the proportion of DE students in a course shows that there exists a tipping point (of about 4\%) where exposure to DE peers starts to have an effect on non-DE community college students.

Our main results indicate that a one standard deviation increase in the proportion of DE peers leads to a decrease of 0.02 GPA points or 0.012 standard deviations in the average GPA of non-DE students. The coefficient is moderate in size and comparable to other studies that have examined other kinds of changes in student composition. For comparison purposes, in one study, a one standard deviation increase in the proportion of high school students who were repeating a high school course reduced the average endof-year test score of students taking the course for the first time by 0.015 to 0.036 standard deviations (Lavy, Paserman, \& Schlosser, 2011). Likewise, Carrell and Hoekstra (2010) found that test scores decreased by 0.025 standard deviations per a one standard deviation increase in the proportion of elementary school students coming from troubled families. At the postsecondary level, the effect size varies and is less comparable. Many studies have investigated the effect of roommates or dorm-mates, who may have a very different peer effect than classmates. The effect size we find in the current study lies in the middle range of existing postsecondary studies of changes in student composition in courses. For example, the standardized effect of an increase in peers' academic achievement background (in terms of a one standard deviation increase in academic index and SAT scores) were - $0.030,0.017$, and 0.104 standard deviations of one's GPA, respectively, in studies by Sacerdote (2001), Stinebrickner and Stinebrickner (2006), and 
Zimmerman (2003). Carrell et al. (2009) found the standardized effect to be an increase of 0.072 standard deviations on average GPA.

The results of our study have important implications for the current national discussion about dual enrollment policy. During the past two decades, surging demand from students, institutions, and policymakers has driven an increase in college coursework offerings for high school students (College Board, 2018). The main impetus behind the rapid expansion of DE appears to be the desire to increase postsecondary participation while reducing costs for students and overall time to earn a postsecondary degree (Boswell, 2001). Yet, the impacts of the expansion of DE on non-DE community college enrollees have not been systematically examined. Our results suggest that there are modest unintended costs associated with this expansion. We find that non-DE community college students start to experience negative effects if a typical classroom with 23 students on average has at least one DE student. Once that threshold is reached, non-DE community college enrollees are more likely to fail the gateway course. Additional course repetition induced by the lower pass rates and performance as a result of DE peers presents not only economic costs to students (and institutions) but may also lead to less visible costs for non-DE community college students in terms of academic confidence, motivation, and self-efficacy. Critics of dual enrollment have noted disparities in access to and participation in DE among different subpopulations (Fink et al., 2017), raising the concern that DE may primarily serve as a subsidy for students from more affluent backgrounds. Non-DE community college enrollees come disproportionately from disadvantaged backgrounds; if their educational opportunities are further compromised as a result of sharing resources with DE students, then the expansion of dual enrollment may, in fact, exacerbate already large inequities in college success and completion.

On the other hand, DE students in community colleges may benefit community colleges and their non-DE students in ways that are important for future study but are beyond the scope of our analysis. As community college enrollment has fallen since about 2010, the increase in DE has provided colleges with tuition dollars that have helped to keep their revenue stable. As a result, community colleges can support facilities, student services, and enhancements that they would otherwise not be able to afford. The 
boost in DE students may also allow colleges to increase the variety of course offerings and course sections with more convenient times and locations.

While DE is likely to continue to grow, in part as a result of these potential benefits, it is important for college administrators and instructors to be aware of the possible challenges that $\mathrm{DE}$ programs present to the learning experiences of non-DE community college enrollees. This paper is unable to test for the specific mechanisms through which DE peers influence non-DE community college enrollees. Perhaps in courses with relatively greater proportions of DE students, instructors tend to devote more attention to these younger learners to help them adapt, leaving the remaining students with less support; or perhaps in courses with greater proportions of less adaptable DE students, interpersonal interactions and group projects are more challenging and less effective, which hurts the course performance of the majority of the students. Non-DE community college students may also get discouraged when they perceive that they are ranked lower following the addition of high-achieving DE students. Future research examining the mechanisms of peer effects in community college classrooms may wish to study these possibilities. Understanding the specific mechanisms will provide insights on ways to improve student support in classes with large proportions of DE students. For example, if DE peers mainly influence their non-DE community college classmates through less effective peer interactions and group projects, instructors could implement course policies and practices that would allow them to monitor student interactions more closely and detect student disengagement in a timely manner. Given the growth of DE programs nationally, it is important to understand how such programs influence all students who are affected by them and to ensure the quality of learning among all students. 


\section{References}

Allen, D., \& Dadgar, M. (2012). Does dual enrollment increase students' success in college? Evidence from a quasi-experimental analysis of dual enrollment in New York City. New Directions for Higher Education, 2012(158), 11-19. https://doi.org/10.1002/he.20010

An, B. P. (2013). The impact of dual enrollment on college degree attainment: Do lowSES students benefit? Educational Evaluation and Policy Analysis, 35(1), 57-75. https://doi.org/10.3102/0162373712461933

An, B. P., \& Taylor, J. L. (2019). A review of empirical studies on dual enrollment: Assessing educational outcomes. In M. B. Paulsen \& L. W. Perna (Eds.), Higher education: Handbook of theory and research (vol. 34, pp. 99-151). Springer.

Andrews, H. A., \& Marshall, R. P. (1991). Challenging high school honor students with community college courses. Community College Review, 19(1), 47-51. https://doi.org/10.1177/009155219101900109

Betts, J. R., \& Zau, A. (2004). Peer groups and academic achievement: Panel evidence from administrative data. Unpublished manuscript.

Boozer, M., \& Cacciola, S. E. (2001). Inside the 'black box' of Project STAR: Estimation of peer effects using experimental data (Center Discussion Paper No. 832). New Haven, CT: Yale University, Economic Growth Center.

Borman, G. D., \& Hewes, G. M. (2002). The long-term effects and cost-effectiveness of Success for All. Educational Evaluation and Policy Analysis, 24(4), 243-266. https://doi.org/10.3102/01623737024004243

Boswell, K. (2001). State policy and postsecondary enrollment options: Creating seamless systems. New Directions for Community Colleges, 2001(113), 7-14. https://doi.org/10.1002/cc.3

Burke, M. A., \& Sass, T. R. (2013). Classroom peer effects and student achievement. Journal of Labor Economics, 31(1), 51-82. https://doi.org/10.1086/666653

Calcagno, J. C., Crosta, P., Bailey, T., \& Jenkins, D. (2007). Does age of entrance affect community college completion probabilities? Evidence from a discrete-time hazard model. Educational Evaluation and Policy Analysis, 29(3), 218-235. https://doi.org/10.3102/0162373707306026

Carrell, S. E., Fullerton, R. L., \& West, J. E. (2009). Does your cohort matter? Measuring peer effects in college achievement. Journal of Labor Economics, 27(3), 439-464. https://doi.org/10.1086/600143 
Carrell, S. E., \& Hoekstra, M. L. (2010). Externalities in the classroom: How children exposed to domestic violence affect everyone's kids. American Economic Journal: Applied Economics, 2(1), 211-228. https://doi.org/10.1257/app.2.1.211

Catron, R. (2001). Dual enrollment in Virginia. New Directions for Community Colleges, 2001(113), 51-58. https://doi.org/10.1002/cc.8

College Board. (2018) College credit in high school: Working group report. New York, NY: Author.

Conley, D. T. (2008). Rethinking college readiness. New Directions for Higher Education, 2008(144), 3-13. https://doi.org/10.1002/he.321

Denning, J. T., Murphy, R., \& Weinhardt, F. (2018). Class rank and long-run outcomes (IZA Discussion Paper No. 11808). Bonn, Germany: IZA Institute of Labor Economics.

Duflo, E., Dupas, P., \& Kremer, M. (2011). Peer effects, teacher incentives, and the impact of tracking: Evidence from a randomized evaluation in Kenya. American Economic Review, 101(5), 1739-1774. https://doi.org/10.1257/aer.101.5.1739

Elsner, B., \& Isphording, I. E. (2017). A big fish in a small pond: Ability rank and human capital investment. Journal of Labor Economics, 35(3), 787-828. https://doi.org/10.1086/690714

Elsner, B., \& Isphording, I. E. (2018). Rank, sex, drugs, and crime. Journal of Human Resources, 53(2), 356-381. https://doi.org/10.3368/jhr.53.2.0716-8080R

Ficano, C. C. (2012). Peer effects in college academic outcomes-Gender matters! Economics of Education Review, 31(6), 1102-1115. https://doi.org/10.1016/j.econedurev.2012.07.012

Fink, J. (2018, November 5). How does access to dual enrollment and Advanced Placement vary by race and gender across states? [Blog post]. Retrieved from https://ccrc.tc.columbia.edu/easyblog/access-dual-enrollment-advancedplacement-race-gender.html

Fink, J., Jenkins, D., \& Yanagiura, T. (2017). What happens to students who take community college "dual enrollment" courses in high school? New York, NY: Columbia University, Teachers College, Community College Research Center.

Freeman, T. M., Anderman, L. H., \& Jensen, J. M. (2007). Sense of belonging in college freshmen at the classroom and campus levels. Journal of Experimental Education, 75(3), 203-220. https://doi.org/10.3200/JEXE.75.3.203-220

Gerber, C. (1987). High school/college brief. Supplement to AACJC Letter, 242, 1-4. 
Giani, M., Alexander, C., \& Reyes, P. (2014). Exploring variation in the impact of dualcredit coursework on postsecondary outcomes: A quasi-experimental analysis of Texas students. High School Journal, 97(4), 200-218. https://doi.org/10.1353/hsj.2014.0007

Hemelt, S. W., Schwartz, N., \& Dynarski, S. M. (2019). Dual-credit courses and the road to college: Experimental evidence from Tennessee (IZA Discussion Paper No. 12481). Bonn, Germany: IZA Institute of Labor Economics.

Herzog, S. (2005). Measuring determinants of student return vs. dropout/stopout vs. transfer: A first-to-second year analysis of new freshmen. Research in Higher Education, 46(8), 883-928. https://doi.org/10.1007/s11162-005-6933-7

Holmes, W. H. (1912). School organization and the individual child: A book for school executives and teachers, being an exposition of plans that have been evolved to adapt school organization to the needs of individual children, normal, supernormal and subnormal. Davis Press.

Horn, L., \& Nevill, S. (2006). Profile of undergraduates in U.S. postsecondary education institutions, 2003-04: With a special analysis of community college students (NCES 2006-184). Washington, DC: U.S. Department of Education, Institute of Education Sciences, National Center for Education Statistics.

Hoxby, C. (2000). Peer effects in the classroom: Learning from gender and race variation (NBER Working Paper No. 7867). Cambridge, MA: National Bureau of Economic Research.

Hoxby, C. M., \& Avery, C. (2012). The missing "one-offs": The hidden supply of highachieving, low income students (NBER Working Paper No. 18586). Cambridge, MA: National Bureau of Economic Research.

Hoxby, C. M., \& Weingarth, G. (2005). Taking race out of the equation: School reassignment and the structure of peer effects. Working paper.

Hughes, K. L., \& Edwards, L. (2012). Teaching and learning in the dual enrollment classroom. New Directions for Higher Education, 2012(158), 29-37. https://doi.org/10.1002/he.20012

Imberman, S. A., Kugler, A. D., \& Sacerdote, B. I. (2012). Katrina's children: Evidence on the structure of peer effects from hurricane evacuees. American Economic Review, 102(5), 2048-2082. https://doi.org/10.1257/aer.102.5.2048

Jenkins, R. (2013, February 12). Serving our dual-enrollment students. The Chronicle of Higher Education. Retrieved from https://www.chronicle.com

Jones, S. J. (2014). Student participation in dual enrollment and college success. Community College Journal of Research and Practice, 38(1), 24-37. https://doi.org/10.1080/10668926.2010.532449 
Karp, M. M. (2012). “I don't know, I've never been to college!” Dual enrollment as a college readiness strategy. New Directions for Higher Education, 2012(158), 2128. https://doi.org/10.1002/he.20011

Karp, M. M., Calcagno, J. C., Hughes, K. L., Jeong, D. W., \& Bailey, T. R. (2007). The postsecondary achievement of participants in dual enrollment: An analysis of student outcomes in two states. New York, NY: Columbia University, Teachers College, Community College Research Center.

Lavy, V., Paserman, M. D., \& Schlosser, A. (2011). Inside the black box of ability peer effects: Evidence from variation in the proportion of low achievers in the classroom. Economic Journal, 122(559), 208-237. https://doi.org/10.1111/j.14680297.2011.02463.x

Lavy, V., Silva, O., \& Weinhardt, F. (2009). The good, the bad and the average: Evidence on the scale and nature of ability peer effects in schools. Journal of Labor Economics, 30(2), 367-414. https://doi.org/10.1086/663592

Lefgren, L. (2004). Educational peer effects and the Chicago public schools. Journal of Urban Economics, 56(2), 169-191. https://doi.org/10.1016/j.jue.2004.03.010

Lyle, D. S. (2007). Estimating and interpreting peer and role model effects from randomly assigned social groups at West Point. Review of Economics and Statistics, 89(2), 289-299. https://doi.org/10.1162/rest.89.2.289

Marsh, H. W., Seaton, M., Trautwein, U., Lüdtke, O., Hau, K.-T., O’Mara, A. J., \& Craven, R. G. (2008). The big-fish-little-pond-effect stands up to critical scrutiny: Implications for theory, methodology, and future research. Educational Psychology Review, 20(3), 319-350. https://doi.org/10.1007/s10648-008-9075-6

Miller, T., Kosiewicz, H., Tanenbaum, C., Atchison, D., Knight, D., Ratway, B., ... Levin, J. (2018). Dual-credit education programs in Texas: Phase II. Washington, DC: American Institutes for Research.

Mokher, C. G., \& McLendon, M. K. (2008). Uniting secondary and postsecondary education: An event history analysis of state adoption of dual enrollment policies. American Journal of Education, 115(2), 249-277. https://doi.org/10.1086/595668

Murphy, R., \& Weinhardt, F. (2018). Top of the class: The importance of ordinal rank (NBER Working Paper No. 24958). Cambridge, MA: National Bureau of Economic Research.

Ost, B. (2010). The role of peers and grades in determining major persistence in the sciences. Economics of Education Review, 29(6), 923-934. https://doi.org/10.1016/j.econedurev.2010.06.011 
Ostrove, J. M., \& Long, S. M. (2007). Social class and belonging: Implications for college adjustment. Review of Higher Education, 30(4), 363-389.

https://doi.org/10.1353/rhe.2007.0028

Ran, F. X., \& Xu, D. (2018). Does contractual form matter? The impact of different types of non-tenure track faculty on college students' academic outcomes. Journal of Human Resources. Advance online publication. https://doi.org/10.3368/jhr.54.4.0117.8505r

Reed, M. (2018, October 18). What nobody told me about dual enrollment. Inside Higher $E d$. Retrieved from https://www.insidehighered.com

Sacerdote, B. (2001). Peer effects with random assignment: Results for Dartmouth roommates. Quarterly Journal of Economics, 116(2), 681-704. https://doi.org/10.1162/00335530151144131

Sacerdote, B. (2011). Peer effects in education: How might they work, how big are they and how much do we know thus far? In E. A. Hanushek, S. Manchin, \& L. Woessmann (Eds.), Handbook of the economics of education (vol. 3, pp. 249-277). Elsevier.

Smith, A. (2017, May 31). Double-edged sword of dual enrollment. Inside Higher Ed. Retrieved from https://www.insidehighered.com

Speroni, C. (2011). High school dual enrollment programs: Are we fast-tracking students too fast? (NCPR Working Paper). New York, NY: National Center for Postsecondary Research.

Stinebrickner, R., \& Stinebrickner, T. R. (2006). What can be learned about peer effects using college roommates? Evidence from new survey data and students from disadvantaged backgrounds. Journal of Public Economics, 90(8-9), 1435-1454. https://doi.org/10.1016/j.jpubeco.2006.03.002

Strayhorn, T. (2008). Sentido de pertenencia: A hierarchical analysis predicting sense of belonging among Latino college students. Journal of Hispanic Higher Education, 7(4), 301-320. https://doi.org/10.1177/1538192708320474

Strayhorn, T. L. (2018). College students' sense of belonging: A key to educational success for all students. Routledge.

U.S. Government Accountability Office. (2018). Public high schools with more students in poverty and smaller schools provide fewer academic offerings to prepare for college (Report No. GAO-19-8). Retrieved from https:/www.gao.gov/assets/700/694961.pdf

Whitmore, D. (2005). Resource and peer impacts on girls' academic achievement: Evidence from a randomized experiment. American Economic Review, 95(2), 199-203. https://doi.org/10.1257/000282805774670158 
Xu, D. (2019). Academic performance in community colleges: The influences of parttime and full-time instructors. American Educational Research Journal, 56(2), 368-406. https://doi.org/10.3102/0002831218796131

Zimmer, R. (2003). A new twist in the educational tracking debate. Economics of Education Review, 22(3), 307-315. https://doi.org/10.1016/S0272-7757(02)00055-9

Zimmerman, D. J. (2003). Peer effects in academic outcomes: Evidence from a natural experiment. Review of Economics and Statistics, 85(1), 9-23. https://doi.org/10.1162/003465303762687677

Zinth, J. (2016). Dual enrollment: Student eligibility requirements. Retrieved from http://ecs.force.com/mbdata/MBQuestNB2?Rep=DE1507

Zinth, J., \& Barnett, E. (2018). Rethinking dual enrollment to reach more students: Promising practices. Denver, CO: Education Commission of the States. 


\section{Appendix}

\section{Table A1}

Course Section and Instructor Predictors of Dual Enrollee Exposure at the Section Level

\begin{tabular}{|c|c|c|c|c|}
\hline \multirow[t]{2}{*}{ Outcome: Percentage of DE } & \multicolumn{2}{|c|}{$\begin{array}{l}\text { No course fixed effects } \\
\text { (1) }\end{array}$} & \multicolumn{2}{|c|}{$\begin{array}{c}\text { With course fixed effects } \\
\text { (2) }\end{array}$} \\
\hline & \multicolumn{4}{|c|}{ Panel A. Course Characteristics } \\
\hline Average student age & $-0.012 * * *$ & {$[0.001]$} & $-0.011 * * *$ & {$[0.001]$} \\
\hline Class size & $0.003 * * *$ & {$[0.000]$} & $0.004 * * *$ & {$[0.000]$} \\
\hline Students' average credits earned last term & $-0.002 * * *$ & {$[0.000]$} & $-0.001 *$ & {$[0.000]$} \\
\hline Average credits earned in this subject last term & $0.015^{* * *}$ & {$[0.002]$} & 0.002 & {$[0.003]$} \\
\hline \multirow[t]{2}{*}{ Distance learning method } & $0.021 * * *$ & {$[0.007]$} & $0.013^{*}$ & {$[0.008]$} \\
\hline & \multicolumn{4}{|c|}{ Panel B. Instructor Characteristics } \\
\hline Female & -0.002 & {$[0.006]$} & -0.007 & {$[0.006]$} \\
\hline \multicolumn{5}{|l|}{ Instructor race/ethnicity } \\
\hline Black & $-0.023^{*}$ & [0.013] & $-0.024 *$ & {$[0.012]$} \\
\hline Hispanic & -0.027 & {$[0.030]$} & -0.014 & {$[0.030]$} \\
\hline Asian & -0.025 & {$[0.018]$} & -0.010 & {$[0.018]$} \\
\hline Missing or other & $0.027^{*}$ & {$[0.014]$} & 0.013 & {$[0.014]$} \\
\hline Average age & 0.000 & {$[0.000]$} & 0.000 & {$[0.000]$} \\
\hline \multicolumn{5}{|l|}{ Instructor employment status } \\
\hline Part-time & -0.002 & {$[0.011]$} & -0.013 & {$[0.011]$} \\
\hline Tenure received & -0.006 & {$[0.012]$} & -0.014 & {$[0.013]$} \\
\hline Tenure-track, not yet received tenure & 0.002 & {$[0.014]$} & -0.007 & {$[0.014]$} \\
\hline \multicolumn{5}{|l|}{ Instructor rank } \\
\hline Full professor & $0.041^{* *}$ & {$[0.017]$} & 0.011 & {$[0.017]$} \\
\hline Associate professor & 0.026 & {$[0.017]$} & 0.008 & {$[0.017]$} \\
\hline Assistant professor & 0.019 & {$[0.015]$} & 0.011 & {$[0.015]$} \\
\hline Instructor & $-0.030 * * *$ & {$[0.011]$} & -0.020 & {$[0.012]$} \\
\hline Lecturer & $0.085^{* *}$ & {$[0.035]$} & -0.047 & {$[0.038]$} \\
\hline \multicolumn{5}{|l|}{ Instructor highest degree earned } \\
\hline Bachelor's degree & $-0.033 * *$ & {$[0.014]$} & -0.005 & {$[0.015]$} \\
\hline Master's degree & -0.014 & {$[0.011]$} & -0.000 & {$[0.011]$} \\
\hline Doctoral/law degree & 0.000 & {$[0.014]$} & -0.001 & {$[0.014]$} \\
\hline Mean years taught & 0.003 & {$[0.002]$} & $0.005^{* *}$ & {$[0.002]$} \\
\hline More than two instructors in course & $0.027^{* * *}$ & {$[0.006]$} & $0.025^{* * *}$ & {$[0.006]$} \\
\hline Observations & \multicolumn{2}{|c|}{13,898} & \multicolumn{2}{|c|}{13,898} \\
\hline$R^{2}$ & \multicolumn{2}{|c|}{0.168} & \multicolumn{2}{|c|}{0.228} \\
\hline
\end{tabular}

Note. Robust standard errors are in brackets. All regressions control for section-level student characteristics and contain college-course and term fixed effects.

${ }^{*} p<.1 .{ }^{* *} p<.05 .{ }^{* * *} p<.01$. 
Table A2

Main Results with Sample Containing Prior GPA

\begin{tabular}{lccccc}
\hline & $\begin{array}{c}\text { Passed current } \\
\text { course }\end{array}$ & $\begin{array}{c}\text { Persisted to } \\
\text { end of course }\end{array}$ & GPA & $\begin{array}{c}\text { Repeated } \\
\text { same course }\end{array}$ & $\begin{array}{c}\text { Enrolled in } \\
\text { different course } \\
\text { in same subject }\end{array}$ \\
\hline Percentage of DE peers & $\begin{array}{c}-0.018^{* *} \\
{[0.007]}\end{array}$ & $-0.012^{*}$ & $-0.054^{* *}$ & $0.016^{* * *}$ & -0.007 \\
{$[0.006]$} & {$[0.022]$} & {$[0.006]$} & {$[0.005]$} \\
Sample mean & 0.741 & 0.893 & 2.467 & 0.118 & 0.373 \\
Observations & 172,465 & 172,465 & 154,054 & 172,465 & 172,465 \\
$R^{2}$ & 0.753 & 0.670 & 0.838 & 0.554 & 0.837 \\
\hline
\end{tabular}

Note. Sample includes all student college-level non-gateway course enrollments. Robust standard errors are in brackets and are clustered at the course-by-term and student levels. All regressions have a full set of covariates and include current college-course, student, and term fixed effects. Singletons are included in the regressions. Results are almost identical when excluding singletons from the estimation.

${ }^{*} p<.1 . * * p<.05 . * * * p<.01$. 